\title{
Optimal Design for Metal Additive Manufacturing: An Integrated Computational Materials Engineering (ICME) Approach
}

\author{
S. AMIR H. MOTAMAN (D) ${ }^{1,3}$ FABIAN KIES, ${ }^{1}$ PATRICK KÖHNEN, ${ }^{1}$ \\ MAIKE LÉTANG, ${ }^{1}$ MINGXUAN LIN,${ }^{1}$ ANDREY MOLOTNIKOV ${ }^{2}$ \\ and CHRISTIAN HAASE (iD ${ }^{1,4}$ \\ 1.-ICME Group, Steel Institute, RWTH Aachen University, Aachen, Germany. 2.-Centre for Additive \\ Manufacturing, School of Engineering, RMIT University, Melbourne, VIC, Australia. 3.-e-mail: \\ seyedamirhossein.motaman@iehk.rwth-aachen.de. 4.—e-mail: christian.haase@iehk.rwth-aachen.de
}

We present our latest results on linking the process-structure-propertiesperformance (PSPP) chain for metal additive manufacturing (AM), using a multi-scale and multi-physics integrated computational materials engineering (ICME) approach. The abundance of design parameters and the complex relationship between those and the performance of AM parts have so far impeded the widespread adoption of metal AM technologies for structurally critical load-bearing components. To unfold the full potential of metal AM, establishing a full quantitative PSPP linkage is essential. It will not only help in understanding the underlying physics but will also serve as a powerful and effective tool for optimal computational design. In this work, we illustrate an example of ICME-based PSPP linkage in metal AM, along with a hybrid physics-based data-driven strategy for its application in the optimal design of a component. Finally, we discuss our outlook for the improvement of each part in the computational linking of the PSPP chain.

\section{INTRODUCTION}

Metal additive manufacturing (AM) offers enormous potential for the rapid production of netshaped, geometrically complex, lightweight, minimum-waste and customized metallic parts without the need for the expensive tools required in conventional casting, subtractive or formative manufacturing processes. ${ }^{1-4}$ Typically, metal AM provides high degrees of freedom in all aspects of component design, including alloy selection, (macro-)structural geometry and microstructural features. Some alloying systems that otherwise would require expensive conventional processing can be readily used in AM, such as refractory alloys, ${ }^{3}$ high-manganese steels ${ }^{5-9}$ or titanium aluminides. ${ }^{10}$ One of the central benefits of metal AM lies within its unrivalled flexibility in building highly customized and complex geometries of macroscopic structures.

Recent experimental studies have reported that unique microstructures are formed during AM, which are substantially influenced by the process parameters. ${ }^{6,11-24} \mathrm{AM}$ components having the same shape and size (macroscopic structure) but made using different process parameters possess strikingly different microstructures, and hence mechanical properties. Consequently, the AM process parameters can be controlled to tailor the microstructures. Therefore, one could simultaneously 3D-print the (macroscopic) structure as well as the desirable microstructure depending on the expected in-service performance of the specialized component.

The high dimensionality of design space, multiobjective design requirements, high sensitivity of the AM parts performance to the design, and extremely complex relationships between the design parameters and performance have so far impeded the widespread adoption of metal AM technologies for structurally critical load-bearing components. In this context, multi-scale and multi-physics integrated computational materials engineering (ICME) $^{25}$ for computational (bottom-up) linking of process-(micro)structure-properties-performance $(\mathrm{PSPP})^{26}$ is a viable solution. ${ }^{1,27-34}$ The role of the 
microstructure is of particular importance, as it controls the material inherent mechanical properties but is often neglected in AM component design.

In this paper, we present a systematic ICMEbased approach that can be used for comprehensive and optimal design for AM. Generally, in metal manufacturing, the design space consists of alloy composition, process parameters, and macroscopic geometry of the structure/component, with the design objective being the in-service performance of the final component. The performance depending on the thermo-chemo-mechanical (TCM) service load may include multiple functional aspects, such as specific energy absorption capacity, fatigue strength/life, high-temperature strength, creep resistance, erosion/wear resistance, and/or corrosion resistance. The TCM processing fields, microstructure, and (macroscopic) TCM material properties are treated as design internal/hidden variables, which are directly affected by the design parameters and determine the performance of the final product. The design elements and their interaction in metal additive manufacturing are shown in Fig. 1. It should be noted that, according to the selected metal manufacturing method (which can be various metal AM methods), the chosen alloy family and design criteria, certain constraints are imposed to each element in the design space. The pre-imposed constraints to the design space include the limitation in the chosen alloy family (corresponding to an allowable concentration of the principal element and each alloying element), process parameters which are constrained by the applied AM method (e.g., laser powder bed fusion; LPBF) and the utilized AM machine (e.g., power density of the energy source), and the component geometry which is limited due to the device it will be a part of (e.g., constraints on the component weight, shape and

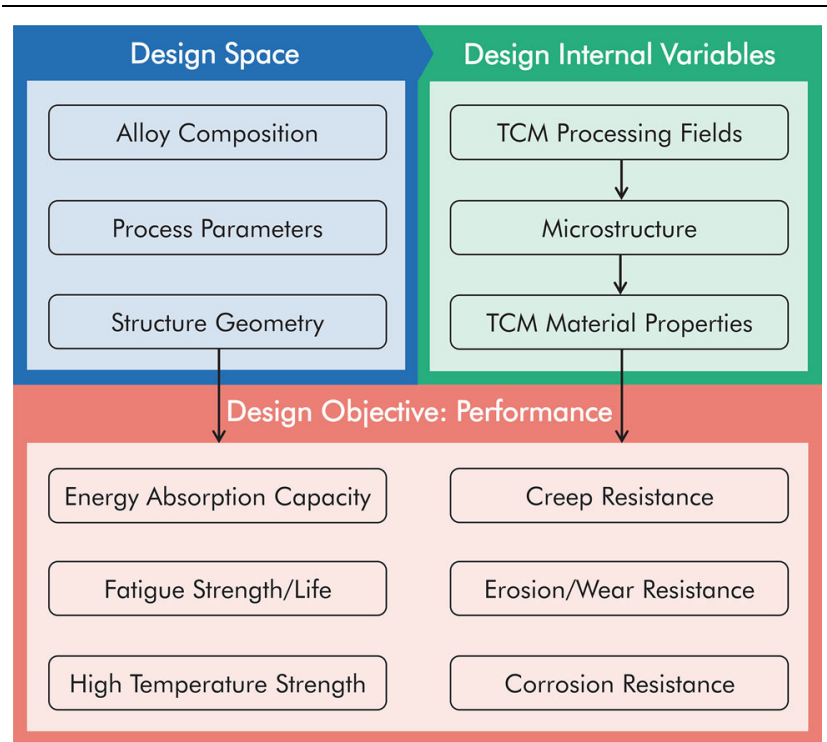

Fig. 1. The design elements and their interaction in metal additive manufacturing. size). Therefore, a constrained subset of the design space is always under consideration. Moreover, the performance space is also constrained by a set of requirements corresponding to the design criteria and the expected/acceptable performance (range) of the final component under the service TCM loads (e.g., the tolerable minimum energy absorption capacity, which preserves the in-service functionality of an additively manufactured lattice structure).

A polycrystal internal structure, i.e., microstructure, with respect to its hierarchal heterogeneity owns the following main distinctive attributes known as the microstructural features, which span across different length scales:

- Meso-scale features Distribution of grain morphology (size, shape and shape-axis orientation), crystallographic texture (orientation and misorientation), phases, twins, and micro-precipitates.

- Submeso-scale / constitutive features Distribution of alloying elements (elemental micro-segregation), dislocation density, porosity/micro-voids (and other defective inclusions), and nano-precipitates.

In our previous experimental-numerical study on high-manganese steel processed by LPBF ${ }^{35}$ it was shown that different aspects of microstructural heterogeneity, in particular grain morphology and crystallographic texture, influence the overall anisotropic mechanical properties, and can be captured using crystal plasticity modeling and computational polycrystal homogenization.

The emerging cross-disciplinary ICME toolset enables a physics-based and hence reliable linkage between process and performance. In this work, we outline an ICME-based strategy, which can be used to connect the AM processing conditions with structure-properties-performance of an AM component and will lead to a better understanding of their relationship. It is hypothesized that such an approach will allow exploiting the unique and flexible local processing conditions of AM for tailoring the local properties of AM components. The proposed framework is illustrated through a simple example, in which the crucial information obtained from the results of each simulation/calculation is passed on to the next one in the chain. This example consists of the following steps:

- Alloy selection for AM using CALPHAD and ab initio/first-principles calculations based on density functional theory (DFT).

- Finite element (FE) simulation of thermal field during AM.

- Simulation of microstructure evolution during AM (using the results of thermal field simulation), by phase field (PF) and kinetic Monte Carlo (KMC) models.

- Crystal plasticity (CP) simulation of macroscopic plastic flow properties by a physics-based constitutive model and using the full field method 
for computational polycrystal homogenization through a fast Fourier transform-based (FFTbased) spectral solver.

- FE simulation of the performance of macroscopic structure using the CP simulation results.

In the present case study, single-phase austenitic high-manganese steel was selected as the model alloy and processed by LPBF to fabricate a lattice structure which is ultimately subjected to a service compressive load for an application corresponding to its specific energy absorption capacity (energy absorption capacity normalized by the weight of the structure).

\section{ALLOY SELECTION}

The design space is initially constrained by selecting a limited set of chemical compositions (within an alloy family) using rapid screening of alloy compositions based on the presumed (TCM) properties. The approach adopted for the present study combined CALPHAD and DFT calculations, as schematically illustrated in Fig. 2.

First, the compositional subspace is computationally screened by CALPHAD and thermodynamicsbased models. In the present study, the aim was to design a single-phase face-centered cubic (fcc) highmanganese steel as the model alloy. Therefore, the vast compositional space was constrained to a subspace associated with the high-manganese steel family. Such an alloy remains single-phase during $\mathrm{AM}$, which reduced the number of possible design internal variables in this case study. Further, in the selected alloy family, the activation of twinninginduced plasticity, ${ }^{36-38}$ which is highly dependent on the microstructural heterogeneities, in particular crystallographic orientation distribution, ${ }^{35}$ was used to promote a high strain hardening (rate) and hence energy absorption capacity (see "Mechanical Properties" and "Performance" sections). The PrecHiMn-04 database ${ }^{39}$ was used for (thermodynamics-based phase stability) CALPHAD calculations within the Fe-Mn-Al-C chemistry subspace by Thermo-Calc software. Moreover, thermodynamicsbased stacking fault energy (SFE) calculations were performed for the selected alloy family. ${ }^{38,40,41} \mathrm{DFT}-$ based ab initio calculations were subsequently performed to derive phase stabilities and energetic material properties, such as the SFE, ${ }^{42-48}$ lattice and elastic constants, ${ }^{49,50}$ and solid solution strength. $^{51-57}$ We selected an alloy with an SFE being sufficiently low to promote deformation twinning and, at the same time, sufficiently high to avoid martensitic phase transformation during deformation. Subsequently, alloys processed by different AM methods, with the elemental composition X30MnAl23- $x$ ( $x=0-2$ wt.\% Al) were experimentally screened. ${ }^{6}$ The alloy X30MnAl23-1 was identified as single-phase fcc with high work-hardening capacity and, therefore, serves as a model alloy for the present ICME study. In addition, a similar methodology has also been successfully employed and validated for high-entropy alloys. ${ }^{58-65}$

\section{THERMAL FIELD}

The output of the alloy selection ("Alloy Selection" section) provided the required input for the work performed in this section, i.e., the thermo-physical properties of the alloy. The temperature $(T)$ field in the melt pool and heat-affected zone play the most significant role in the formation of the as-built microstructure. The grain morphology, texture, segregation of solute elements, and the formation of primary precipitates are known to be affected by the temperature gradient near the solidification front and by the growth velocity. The development

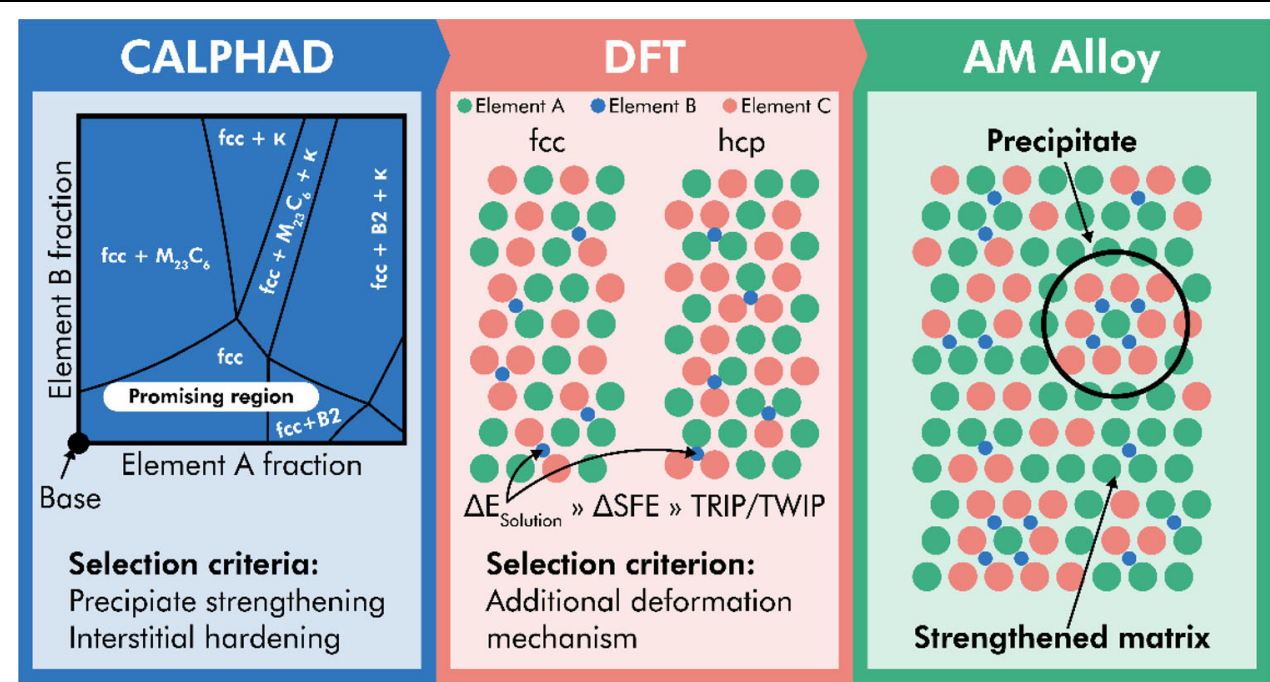

Fig. 2. The alloy selection approach. CALPHAD calculations are first performed to narrow the space of promising chemical compositions. More precise calculation of phase stabilities and energetic material properties are performed using DFT-based models. 
of a stable melt pool depends on the interaction between the moving heat source (laser beam), the material in various states (powder, liquid, and solidified) and the ambient environment. In the past decade, FE-based transient thermal conduction models that originate from laser-welding applications have been employed to simulate the temperature evolution in AM processes. ${ }^{66,67}$ More recently, comprehensive multi-physics models have been developed to simulate the thermal-fluid flow (heat and mass transfer) in the melt pool (using computational fluid dynamics) and the particle dynamics in the powder bed. ${ }^{68-71}$ However, due to complex fluid-structural interactions and extremely high temperature gradients, the computational cost for such type of simulations is prohibitively high for large-scale applications. Therefore, in this work, we used the less demanding FE method (without consideration of fluid flow in the melt pool).

Our earlier work, ${ }^{72}$ demonstrated an FE model for the simulation of melt pool geometry under different scan speeds during LPBF. The implicit thermal solver of FE software ABAQUS was used to numerically simulate the transient thermal field and melt pool geometry, using a moving semiellipsoidal volumetric heat flux defined by the (user-defined) subroutine DFLUX with a Gaussian heat source intensity profile. The temperature-dependent thermal conductivity was adopted from experimental measurements on a similar alloy. ${ }^{73}$ Since the laser radiation interacts mostly with the liquid melt pool during $\mathrm{LPBF},{ }^{74}$ an absorption coefficient of 0.41 for liquid iron irradiated by an Nd-YAG laser was chosen. ${ }^{75}$ Five scanning tracks with a bi-directional scan strategy were modeled. The solution domain was decomposed to the powder bed and solidified material, which were approximated as homogenous and continuous fields. The thermo-physical properties of the material, including liquidus temperature $\left(T_{1}\right)$, solidus temperature $\left(T_{\mathrm{s}}\right)$, specific heat capacity, and latent heat were calculated by Thermo-Calc using the PrecHiMn-04 database. The thermo-physical properties of the powder were determined based on those of the solid and the powder bed density, which was assumed to be a fraction $(40 \%)$ of that of the bulk material. ${ }^{76}$ The user-defined field subroutine (USDFLD) was used to define a state variable $(0 \leq \varphi \leq 1)$, which was initialized with $\varphi=0$ representing the powder. At each material/integration point, once the temperature reached the liquidus temperature $\left(T=T_{1}\right)$, the state variable changed its value to $\varphi=1$ denoting the non-powder (fully liquid or dense solid) state. For $T_{\mathrm{s}} \leq T \leq T_{1}$, the powder density and heat conductivity were linearly interpolated between those of fully solid and liquid states. An example of the simulated temperature field and melt pool geometry during the bi-directional scanning in LPBF of a (rectangular) block structure is shown in Fig. 3.

\section{MICROSTRUCTURE EVOLUTION}

As mentioned earlier, the microstructure has distinctive features at the meso- and submesoscales. Therefore, in order to sufficiently capture the (mechanical) material properties at the macroscale, microstructure development needs to be simulated at both the meso- and submeso-scales. Here, elemental micro-segregation as a decisive submesostructural aspect together with the grain structure at the meso-scale were simulated, respectively using FP and KMC models, based on the information delivered by the alloy selection ("Alloy Selection" section) and thermal field ("Thermal Field" section) calculations/simulations.

\section{Elemental Segregation}

Modeling of elemental micro-segregation during AM requires not only the thermo-physical properties ("Alloy Selection" section) but also the evolution of the temperature field over time during

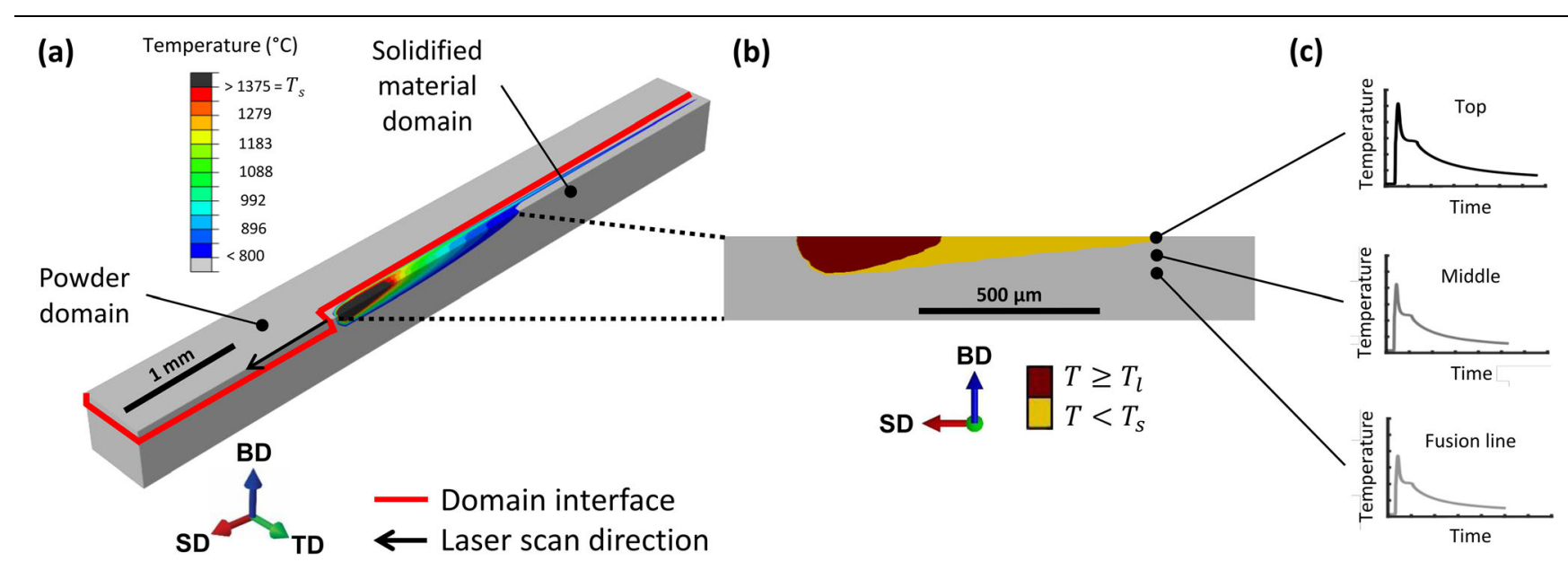

Fig. 3. (a) FE-simulated temperature field, (b) corresponding melt pool geometry, and (c) site-specific temperature evolution during LPBF of a block structure. 
(a)

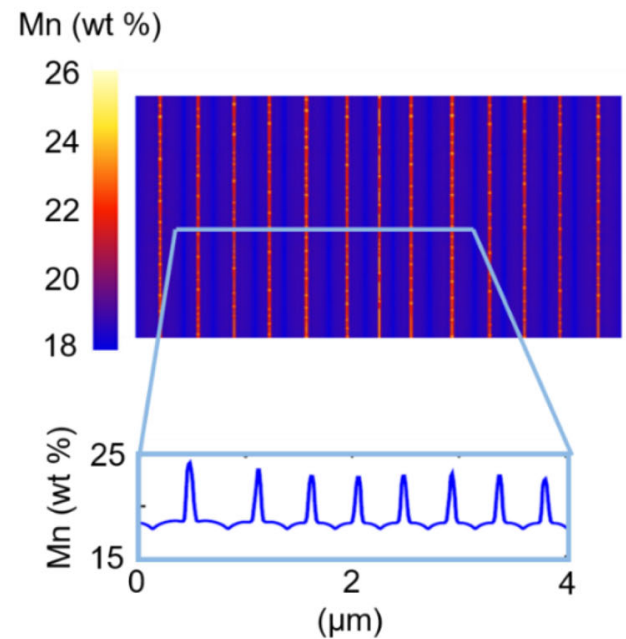

(b)

C (wt \%)

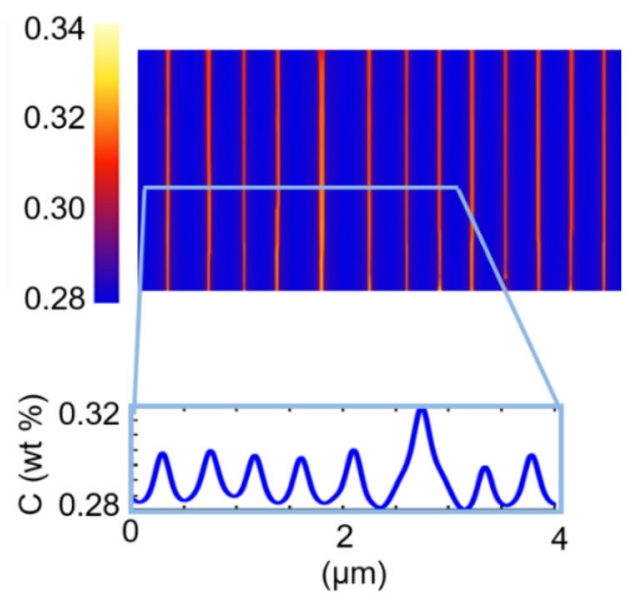

Fig. 4. PF-simulated micro-segregation pattern of (a) manganese and (b) carbon with the corresponding distribution profiles along an intercept line (perpendicular to the build direction).

solidification (“Thermal Field" section). The solidification simulations with a focus on elemental segregation were carried out using the phase-field software MICRESS ${ }^{\circledR}$ based on the multi-phase field approach. ${ }^{77} \mathrm{PF}$ and diffusion equations are derived from a free energy functional. Numerical minimization of the free energy of the multiphase system was performed using Thermo-Calc to simulate the solute partitioning and to evaluate the thermodynamics driving force for phase transformations. This method has been widely used to simulate the microstructure evolution during solidification. In addition to composition and temperature, order parameters ( $\mathrm{PF}$ variables) were used, giving an extra degree of freedom. This parameter can vary continuously from 0 (absence) to 1 (existence) for different phases/grains, so that non-equilibrium processes can be investigated without the necessity to track the interface. ${ }^{77,78}$

A two-dimensional (2D) simulation was performed to study the relationship between the process parameters, the resulting thermal conditions, and the microstructure, including micro-segregation. The FE-simulated thermal field during the LPBF process was used as input. The vertical direction in the modeled (2D) domain is parallel to the build direction of the LPBF sample. The height of the simulated area was chosen in such a way that the total melt pool height is displayed. Since the solidification parameters in the melt pool are different in every position and only a one-dimensional temperature profile can be handled in MICRESS ${ }^{\circledR}$, the melt pool width was not considered, resulting in a $70 \times 10 \mu \mathrm{m}$ simulation domain with a grid size of $0.0125 \mu \mathrm{m}$. Thermodynamics properties were determined using the Thermo-Calc (TCFE9 and MOBFE4) databases. An initial structure was defined by two phases, representing the solidified layer and the melt. Epitaxial growth was assumed.
The height of the initial structure was set to $40 \mu \mathrm{m}$. This height corresponds to the existing substrate height in the modeled area, after lowering the substrate plane by $30 \mu \mathrm{m}$ before adding a new powder layer and remelting. The melt was present in the area above the grains. The melt composition and starting structure were identical. At the boundaries of the simulated domain, insulating boundary conditions were defined. The time step size was automatically selected by the PF solver. The PFsimulated cellular segregation profiles of manganese and carbon (two main alloying elements in the selected alloying system) are shown in Fig. 4 . Since carbon is a fast diffusive interstitial alloying element, the carbon profile appears smoother than that of manganese, which results from back-diffusion of the carbon from the enriched cell boundaries into the cells during solidification and cooling. On the other hand, the substitutional alloying element manganese, with slower diffusivity and lower backdiffusion, remained richer within the inter-dendritic regions. The temperature-dependent diffusion coefficients for all the elements are derived from the coupled Thermo-Calc mobility database MOBFE4.

\section{Grain Structure}

The melt pool dimension as derived from the thermal field simulation along with the process parameters (laser power, spot size, and scanning strategy) served as direct input for simulation of the mesoscopic grain structure formed during LPBF. The meso-scale microstructure (or simply mesostructure) evolution was simulated using a KMC model ${ }^{79}$ which is implemented in the open source SPPARKS Potts-KMC simulator software. After 10 deposited layers, from the center of the simulated volume, the grain structure shown in Fig. 5 was extracted as a representative volume element 
(a)

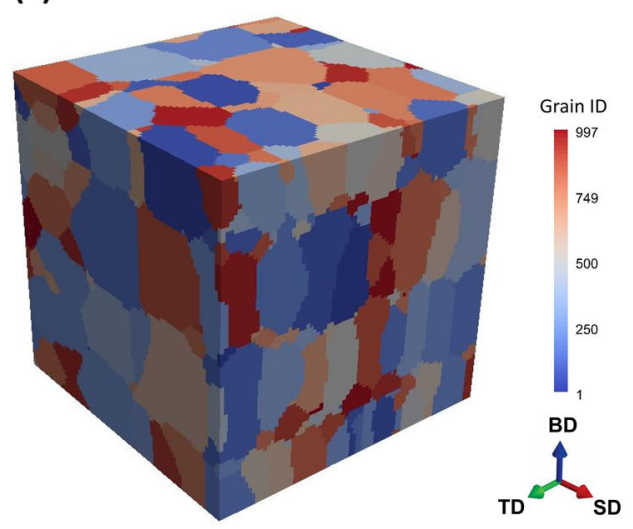

(b)
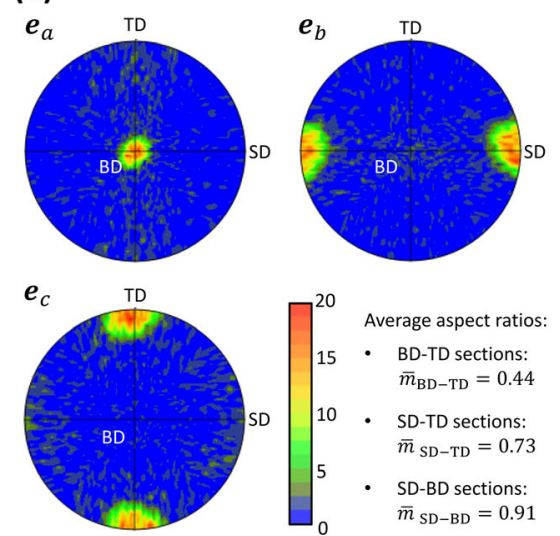

Fig. 5. (a) Grain structure as RVE extracted from the ensemble of grains after 10 additively deposited (LPBF) layers simulated using the KMC model. ${ }^{79}$ (b) Mean grain shape (aspect ratio at orthogonal planes) and grain shape-axis orientation distribution in terms of pole figures with respect to ellipsoidal grain principal axes $\left(\boldsymbol{e}_{a}, \boldsymbol{e}_{b}, \boldsymbol{e}_{c}\right)$, which were analyzed and plotted by DREAM.3D software. ${ }^{80}$

(RVE). As shown in Fig. 5, grain sections on the build direction (BD)-transverse direction (TD) plane and scan direction (SD)-TD plane are dominantly elongated towards $\mathrm{BD}$ and $\mathrm{SD}$, respectively, whereas grain sections on the BD-SD plane are almost equiaxed. This is due to the specifically chosen AM process parameters including the bidirectional scanning pattern (without rotation or switching between SD and TD in each AM layer), and considering the fact that grain growth is favorable along the maximum local heat flow direction. This is in line with the typically observed grain shapes in AM meso-structures, as the grain sections on BD-TD sections are columnar, meaning that they are polarized (having an elongated shape with relatively low aspect ratio and low angle of the major principal axis) along BD. Here, the aspect ratio $(m \equiv b / a$, where $0<m \leq 1)$ for a given grain is defined as the length of minor axes $(b)$ of the best-fit ellipse divided by its major axis length $(a)$.

\section{MECHANICAL PROPERTIES}

The (as-built) AM microstructures have been shown to be highly polarized (strong crystallographic texture and strongly polarized grain morphology), heterogeneous and spatially non-uniform in every possible aspect compared to their traditionally manufactured counterparts. ${ }^{35}$ These inherent microstructural disparities result in a highly anisotropic (macroscopic) plastic flow behavior. Macroscopic mechanical response/properties of such materials can be adequately captured by the full field method for computational polycrystal homogenization using RVE coupled with physics-based CP constitutive modeling.

The RVE extracted using the results of mesostructure simulation ("Grain Structure" section) was used in CP simulations to derive the macroscopic mechanical response of material in terms of homogenized (monotonic) flow curves. The polycrystalline aggregate was set under externally imposed macroscopic boundary conditions corresponding to displacement-controlled uniaxial load with a quasi-static (true) strain rate $\left(\dot{\bar{\varepsilon}}=10^{-3} \mathrm{~s}^{-1}\right)$, which translates to pure deformation periodic boundary conditions on the RVE (Fig. 5). The governing boundary value problem is then solved using the physics-based CP model detailed in Ref. 35 to fulfill the mechanical equilibrium by the FFTbased spectral solver of the modular CP code DAMASK. $^{81}$ The applied CP constitutive model computes the mechanical response as well as evolution and anisotropic interaction of micro-state variables (MSVs) at deformation (slip/twin) systems of meso-scale grid/integration points (or simply meso-points) of the RVE, using physically motivated formulations that take submeso-scale/constitutive effects into account. The constitutive state variables are unipolar and dipolar dislocation densities, as well as twin volume fraction. The incrementally resolved fields (stress, strain and MSVs) at the meso-points are then homogenized over the mesoscopic RVE to give the macroscopic response.

Since the applied constitutive model is based on the underlying physics of crystal plastic deformation, most of the corresponding constitutive/submeso-structural parameters have a clear physical meaning and are adopted from various sources of independent experimental measurements and/or submeso-scale simulations (ab initio, atomistic and discrete dislocation dynamics) associated with the selected alloy composition (X30MnAl23-1). The effective grain size as a constant was determined from the grain size (number and volume fraction) distribution of the KMC-simulated grain ensemble. As mentioned in "Alloy Selection" section, the SFE, as another material constant, was calculated from the chemical composition of the material. The initial dislocation density was estimated as a function of the average cooling rate during solidification. Furthermore, the results of micro-segregation 
simulations ("Elemental Segregation" section) have been used to calculate the variance in the submesoscale distribution of SFE and, subsequently, the parameters associated with the probability density of twin nucleation. The homogenized mechanical response in terms of (flow) stress and strain hardening $\left(\theta \equiv \frac{\partial \sigma}{\partial \varepsilon}\right)$ along with the evolutions of twin (volume) fraction and (unipolar) dislocation density with strain are plotted in Fig. 6.

\section{PERFORMANCE}

The design objective of the present case study was obtaining the deformation behavior and the resulting specific energy absorption capacity of the f2cc, $z$ lattice structure. FE simulations are a useful tool to assess the performance of structural parts under different loading conditions, and offer guidance in the selection of materials and geometrical features of components to optimize their performance. ${ }^{82} \mathrm{FE}$ models are constructed from computer-aided design $(\mathrm{CAD})$ files which describe the geometry of the structural component. The imported geometry is then discretized using finite elements, and specific boundary conditions are applied corresponding to service loads. It is worth noting that the selection of FE type influences the accuracy of the predictions as well as the computation time. ${ }^{83,84}$

Here, we present a FE model of the f2cc, $z$ lattice structure fabricated by LPBF of the alloy X30MnAl23-1 under compressive load (Fig. 7a). The geometry and boundary conditions were adapted from Refs. 6 and 24. The compression specimen consisted of five f2cc, $\mathrm{z}$ unit cells in each direction with $500-\mu \mathrm{m}$-diameter struts. The simulations were performed using the commercial $\mathrm{FE}$ package QForm VX and utilized tetrahedron elements. QForm VX employs an automatic remeshing algorithm as a function of the varying stress field, which allows obtaining an accurate prediction of the structural deformation behavior. The material behavior under plastic deformation was represented as flow curves (true stress response as a function of accumulated plastic strain) with different

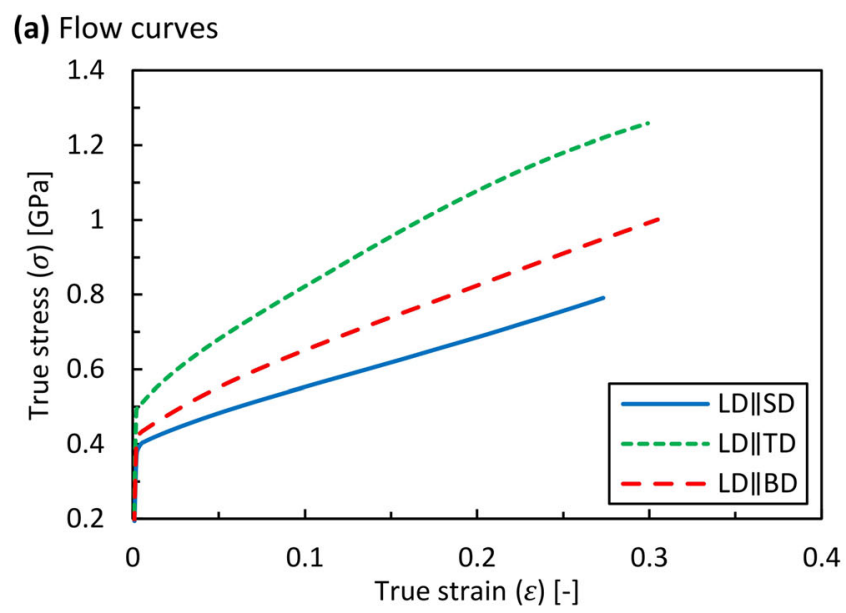

(b) Strain hardening curves

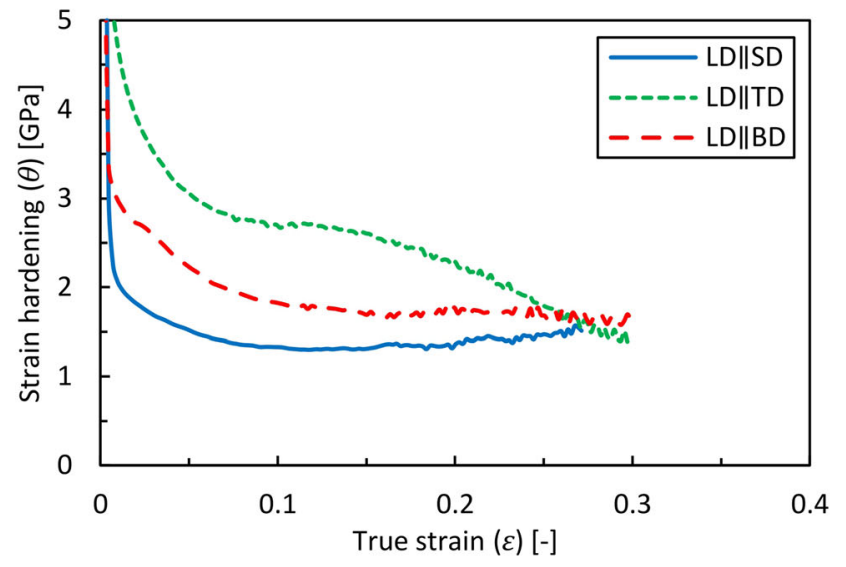

(d) Dislocation density evolution

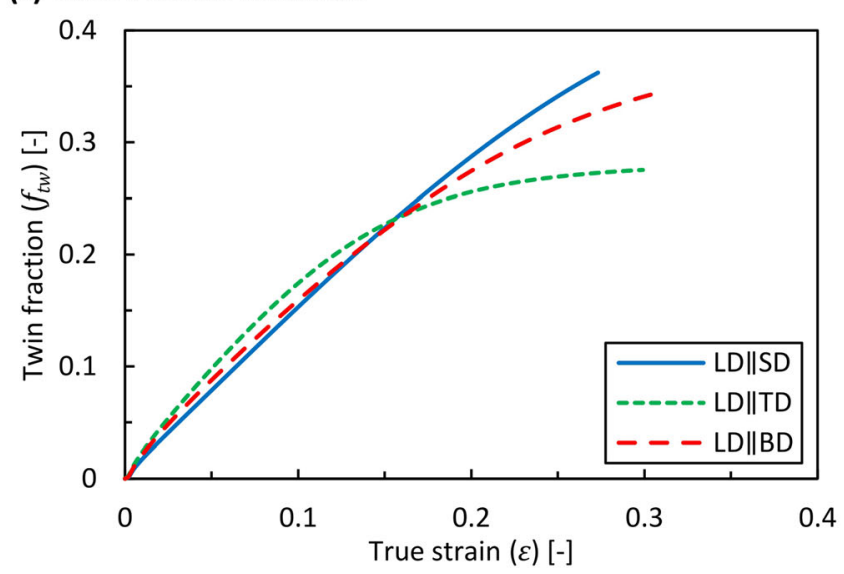

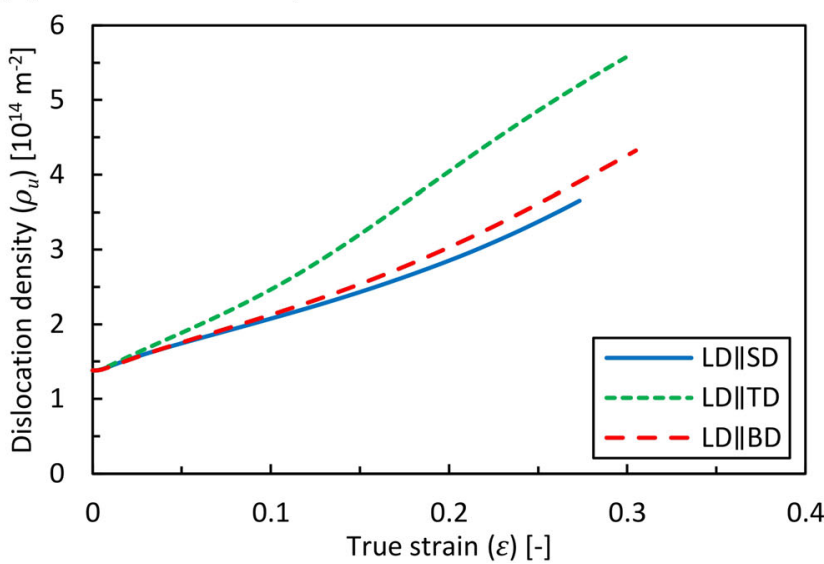

Fig. 6. Simulated homogenized (a) flow curves, (b) strain hardening curves, (c) evolution of twin (volume) fraction, and (d) evolution of (unipolar) dislocation density of/in the high-manganese steel processed by LPBF (using the RVE shown in Fig. 5) under uniaxial tension at $\overline{\dot{\varepsilon}}=10^{-3} \mathrm{~s}^{-1}$ and $T=23^{\circ} \mathrm{C}$ along different axes. 
(a)

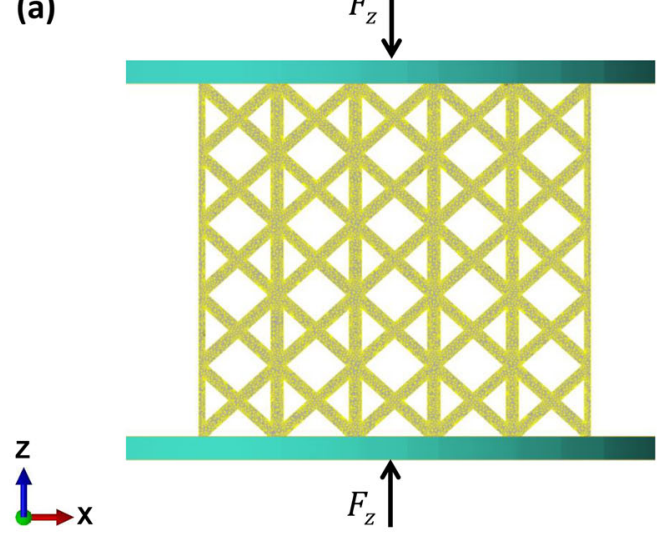

(c)

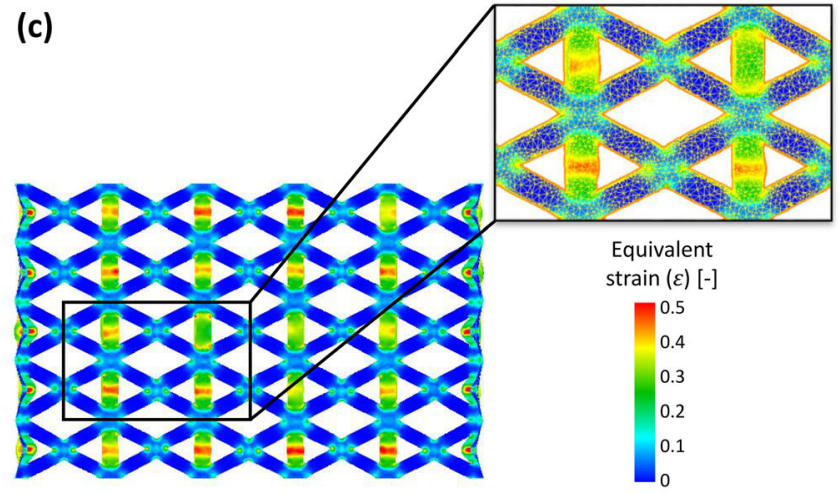

(b)

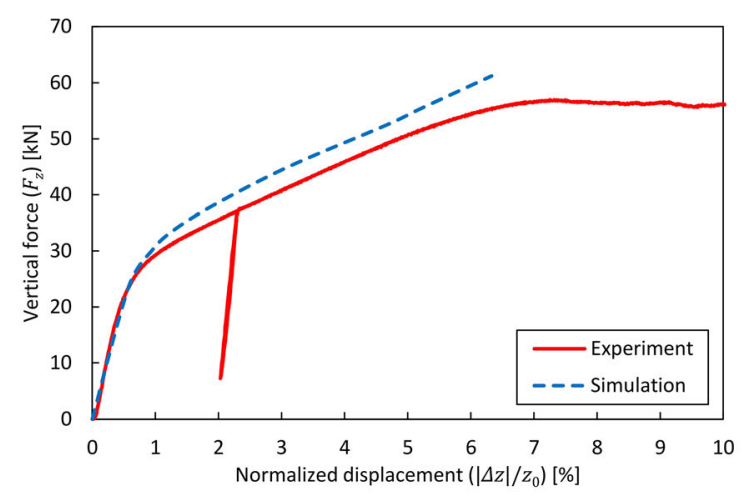

(d)

Axial $\operatorname{strain}\left(\varepsilon_{z z}\right)[\%]$

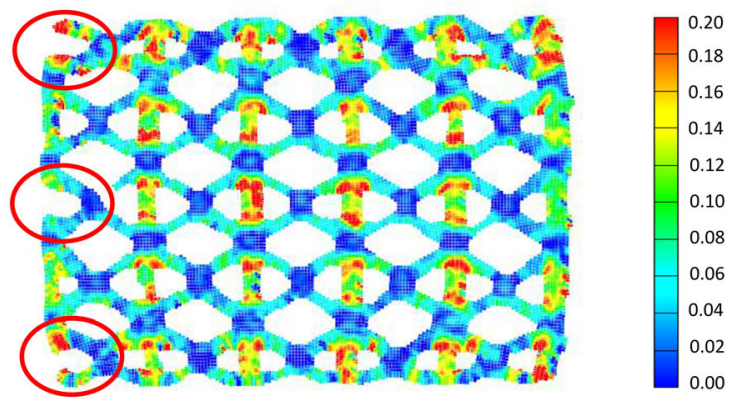

Fig. 7. FE simulation of a compression test of high-manganese steel lattice structure fabricated by LPBF. (a) The FE model of the f2cc, $z$ lattice structure with a fine mesh using tetrahedron elements. (b) Comparison of the experimental and FE-simulated force-displacement responses of the lattice structure. (c) FE-simulated distribution of equivalent (von Mises) strain showing strain localization in the vertical (\|Z) struts. The magnified deformed area illustrates the increased density of tetrahedron elements to capture the localized deformation. (d) Experimentally measured (local) axial $(\| Z$ ) strain distribution using digital image correlation (DIC) at $10 \%$ normalized compressive displacement.

deformation parameters (combination of strain rate and loading axis), which were determined using the computational polycrystal homogenization approach described in "Mechanical Properties" section.

Most FE software packages provide the possibility of integrating advanced material models, and permit the user to trace the evolution of MSVs. Figure 7c shows an example of the local (equivalent) strain distribution in the lattice structure during compressive deformation measured using digital image correlation (DIC). The major deformation in the lattice structure is accommodated by the vertical $(\| Z)$ struts, ${ }^{24}$ as their axes are parallel to the loading direction $(\| \mathrm{LD})$. Additional areas of high strain concentrations are observed at the strut junctions (Fig. 7c). These zones of (macro-scale) strain localization lead to failure of the struts in these regions. Similar observations have also been reported in Refs. 24 and 84. The comparison of FEsimulated and experimental force-displacement responses of the lattice structure (Fig. 7b) implies a reliable numerical prediction of the lattice structure performance for the elastic and elasto-plastic deformation regimes. However, simulation of the force-displacement response of the lattice structure in the deformation regimes after the onset of damage initiation (here, corresponding to the normalized compressive displacement of $6 \%$ ) requires coupling the elasto-plastic constitutive model with a suitable ductile damage model. Incorporation of a damage model which accounts for the processinduced defects in the as-built structure, including internal pores/voids, surface roughness, ${ }^{85}$ and deviations in the morphology of the struts, would also enhance the agreement between the simulated local strain distributions and those obtained from the corresponding DIC maps (Fig. 7c and d). In particular, Fig. 7d shows the failure in some (circled) of the struts at relatively early stages of deformation. The experimental result also shows variations in strut diameter and some minor bulging due to friction in the interfaces of the lattice structure and tools. Despite these differences, which become more pronounced with increased accumulation of the plastic strain and damage, the simulation was able to predict force-displacement responses (performance) of the lattice structure in the early stages of deformation where damage is not dominant. Nonetheless, the (simulated) force is slightly overestimated (Fig. 7b). 


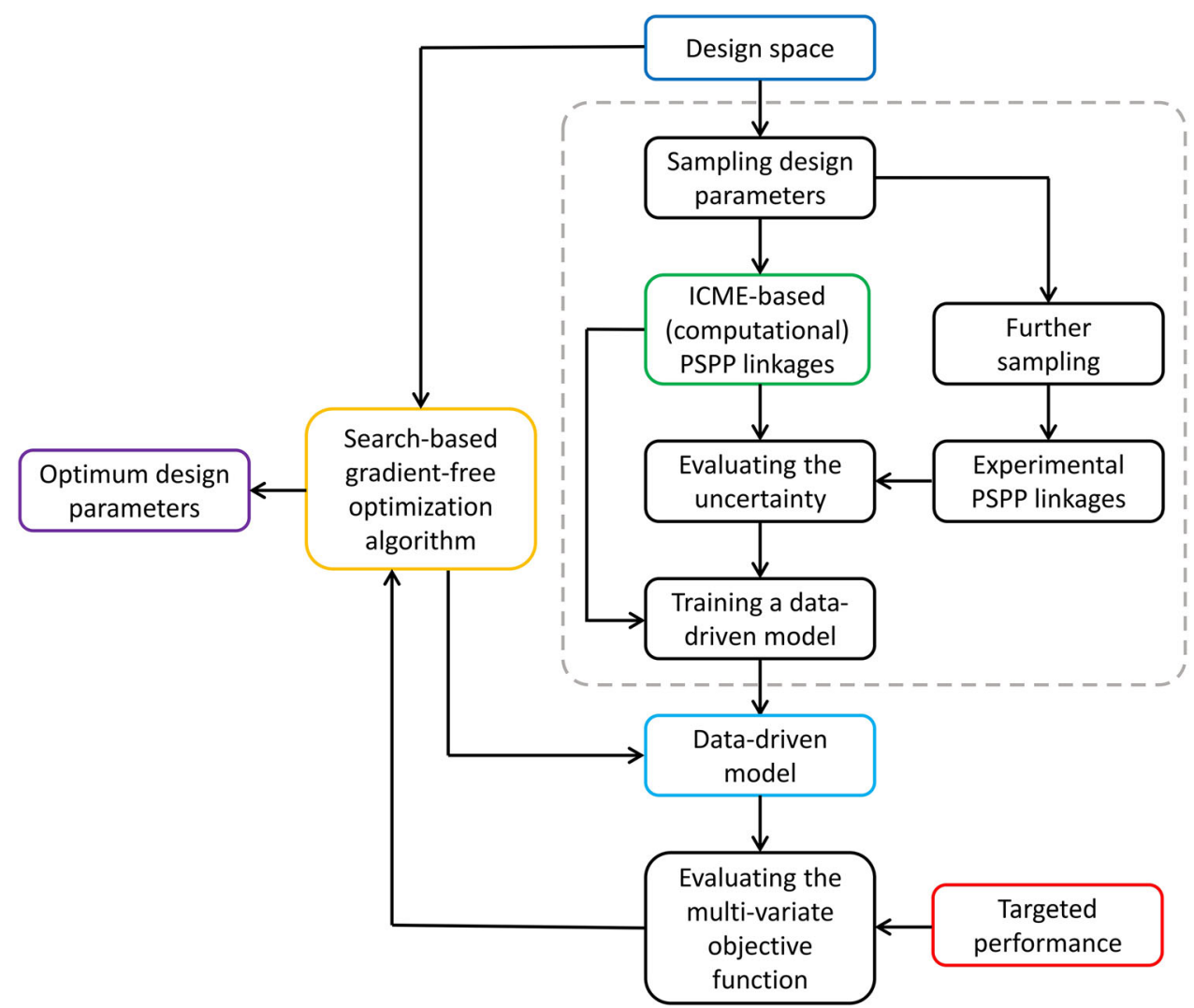

Fig. 8. Workflow of the proposed hybrid ICME-based data-driven method as a performance-oriented optimal design strategy for metal AM.

\section{OPTIMAL DESIGN}

Once the ICME-based PSPP linkage is established, the search-predict-optimize (SPO) cycle can be invoked for the optimal selection of design parameters from the design space, which consists of alloy composition, process parameters, and (macroscopic) structural geometry. However, a rigorous ICME-based PSPP linkage is quite (computationally) expensive and complex. Therefore, we propose an efficient hybrid ICME-based data-driven modeling as a performance-oriented optimal design strategy for metal AM, which its workflow is demonstrated in Fig. 8. It consists of the following steps:

I. Decomposition of the multi-dimensional design space into a finite number of domains according to the specific ranges of interest for each dimension; and sampling the design parameters from the aforementioned domains, using a design-of-experiments method.

II. Predicting the performance for design parameter combinations via the ICME-based PSPP linkage, as illustrated in Fig. 9.

III. Establishing experimental PSPP linkages for a few combinations of design parameters and evaluating the uncertainty in the ICMEbased PSPP linkages.

IV. Training a data-driven model by the physics- based performance predictions associated with the sampled design parameters. Datadriven Gaussian process regression models, which are kernel-based and non-parametric, seem to be suitable candidates to emulate the ICME-based PSPP linkages. Such surrogate models, which are already implemented in MATLAB and Python, can be readily used.

V. Defining a multi-variate objective function for minimization based on the targeted performance features.

VI. Application of the trained data-driven model for performance optimization through the closed-loop SPO iterations using a searchbased gradient-free optimization algorithm to minimize the multi-variate objective function.

VII. Validating and fine-tuning the "optimum" set of design parameters using ICME-based PSPP linkages followed by experimental verification of the performance associated with the outcome design parameters.

\section{REMAINING CHALLENGES}

Despite the fact that the demonstrated work covers all the ICME-based links in the PSPP chain, there are several remaining challenges. Enhanced 


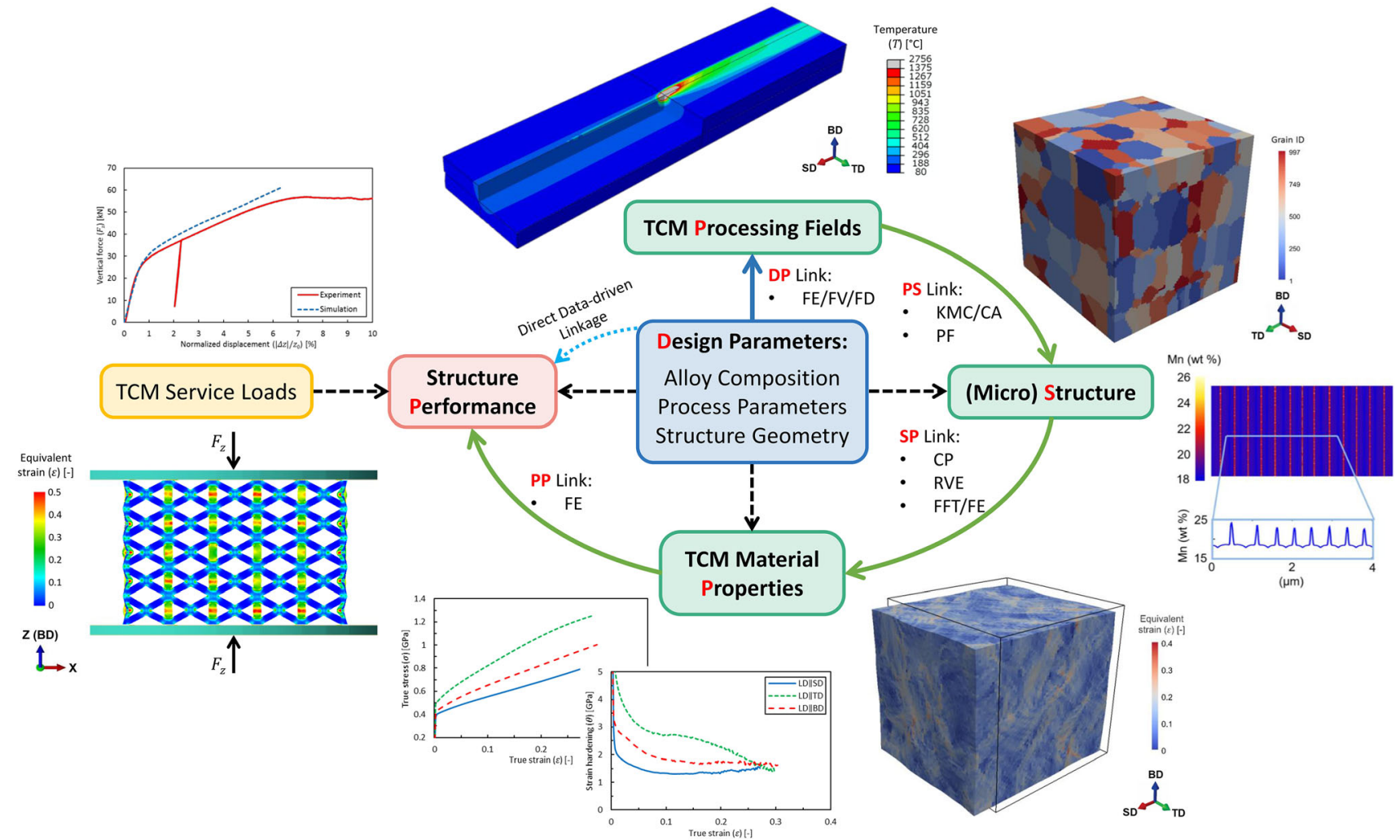

Fig. 9. Overview of the ICME-based PSPP linkage for performance (specific energy absorption capacity) prediction of a lattice structure, made of high-manganese steel, additively manufactured by LPBF.

accuracy in each link can be achieved by relaxing some of the initial assumptions and integration of more sophisticated models:

- Process-structure (PS) link convective melt pool dynamics and powder bed particle dynamics modeling can be used to inform/improve the presented relatively efficient and simple model for the simulation of thermal field during AM. The current model can be extended to include the effects of successive build layers and their associated cyclic heating of lower layers on the evolution of thermal field. Moreover, formation of macro-scale residual stresses during AM due to non-equilibrium cooling, which can be significant depending on the process parameters and structural geometry, is not currently considered. Finally, the applied microstructure evolution models do not account for the evolution of texture, phases, precipitates, micro-voids, and dislocation density. Therefore, there is a critical need for efficient and comprehensive microstructure evolution models which are coupled with the processing fields. The cellular automata models for microstructure evolution that are coupled with finite element/volume/difference thermal models seem to be promising. ${ }^{86-93}$ These types of models have recently been applied for simulation of grain morphology and crystallographic texture during various metal AM processes.
- Structure-properties SP link the utilized model for the structure-properties linkage is robust and computationally efficient. However, it does not account for a number of physical phenomena that can be significant in some regimes. These physical phenomena are the deformation-twin thickening, dynamic/static pinning of dislocations, strain-path change, tension-compression asymmetry, slip transfer at microstructural interfaces and, most importantly, damage and fracture. Computationally expensive but advanced (continuum) gradient-based crystal plasticity constitutive models with dislocation fluxes ${ }^{94,95}$ that are coupled with phase field models for damage ${ }^{96}$ and twinning ${ }^{97}$ can be used to inform/improve the applied more efficient model.

- Properties-performance PP link the model used for performance simulation takes the flow curves corresponding to different deformation parameters (combination of strain rate, temperature and loading axis) as input. These flow curves were provided from the SP simulations. However, since, generally, the macro-scale material points in the performance simulations are under complex multi-axial and cyclic loading conditions with different and varying deformation parameters, the applied modeling approach, which is not physics-based and history-dependent, may lead to inaccurate predictions. This inaccuracy 
becomes significant when the mechanical response of the material is highly sensitive to deformation parameters, such as those observed in the highly anisotropic stress response in AM materials. One solution is the application of mean-field methods for computational polycrystal homogenization rendering the unique macroscale material response as a function of evolving micro-state variables and multi-axial deformation parameters, e.g., self-consistent methods. ${ }^{98-100}$ Moreover, nonlocal microstructural constitutive modeling at the macro-scale ${ }^{101}$ implemented in a thermo-micro-mechanical framework, ${ }^{102}$ is also a viable solution. In this context, the applied mean-field/nonlocal constitutive model must adequately account for the microstructural features, such as grain morphology and crystallographic texture, which are known to control the macroscopic anisotropy in mechanical response of the polycrystalline aggregates. Such mean-field or nonlocal models can be informed by the results of full-field SP simulations. Furthermore, another important aspect which is currently neglected in the depicted PP link is damage. For a more precise and comprehensive performance simulation of the macroscopic structure, a physics-based continuum damage model, which accounts for defects such as surface roughness and voids, ${ }^{103-108}$ should be coupled with the applied elasto-plastic constitutive model.

\section{CONCLUDING REMARKS}

A versatile ICME-based approach for optimal design for metal additive manufacturing has been introduced. The following concluding remarks can be made:

- Due to the vastness and multi-dimensionality of the design space and the highly complex relationship between the design parameters and outcome performance, the optimal design is only achievable computationally, as it will dramatically reduce time and effort in experimentation and provide accelerated pathways to explore the design space.

- We proposed a hybrid physics-based data-driven strategy for optimizing the performance of additively manufactured products by selecting the optimum design parameters from the design space. The physics-based ICME methods allow for the capturing of the prevalent physical mechanisms, whereas the combination with data-driven approaches enables computationally efficient acquisition of the PSPP linkages.

- The approach outlined in this paper will provide a roadmap for widespread adoption of loadbearing additively manufactured metallic components.

\section{ACKNOWLEDGEMENTS}

Open Access funding provided by Projekt DEAL. The authors would like to thank the German Research Foundation (Deutsche Forschungsgemeinschaft, DFG) for the support of the depicted research within the Cluster of Excellence "Internet of Production"-CRD C2 "Enablers and Tools" and within the Collaborative Research Center (SFB) 761 "Steel-ab initio; quantum mechanics guided design of new Fe based materials". A.M. and C.H. would also like to acknowledge the support of the Australia-Germany Joint Research Co-operation Scheme (German Academic Exchange Service (DAAD)/Universities Australia, Project ID 57388267).

\section{OPEN ACCESS}

This article is licensed under a Creative Commons Attribution 4.0 International License, which permits use, sharing, adaptation, distribution and reproduction in any medium or format, as long as you give appropriate credit to the original author(s) and the source, provide a link to the Creative Commons licence, and indicate if changes were made. The images or other third party material in this article are included in the article's Creative Commons licence, unless indicated otherwise in a credit line to the material. If material is not included in the article's Creative Commons licence and your intended use is not permitted by statutory regulation or exceeds the permitted use, you will need to obtain permission directly from the copyright holder. To view a copy of this licence, visit $h$ ttp://creativecommons.org/licenses/by/4.0/.

\section{REFERENCES}

1. W.J. Sames, F.A. List, S. Pannala, R.R. Dehoff, and S.S. Babu, Int. Mater. Rev. (2016). https://doi.org/10.1080/0950 6608.2015.1116649.

2. D.D. Gu, W. Meiners, K. Wissenbach, and R. Poprawe, Int. Mater. Rev. (2013). https://doi.org/10.1179/1743280411Y.0 000000014.

3. T. DebRoy, H.L. Wei, J.S. Zuback, T. Mukherjee, J.W. Elmer, J.O. Milewski, A.M. Beese, A. Wilson-Heid, A. De, and W. Zhang, Prog. Mater. Sci. (2018). https://doi.org/10.1016/ j.pmatsci.2017.10.001.

4. D.L. Bourell, Annu. Rev. Mater. Res. (2016). https://doi.org/ 10.1146/annurev-matsci-070115-031606.

5. C. Haase, J. Bültmann, J. Hof, S. Ziegler, S. Bremen, C. Hinke, A. Schwedt, U. Prahl, and W. Bleck, Materials (Basel, Switzerland) (2017). https://doi.org/10.3390/ma100 10056.

6. F. Kies, P. Köhnen, M.B. Wilms, F. Brasche, K.G. Pradeep, A. Schwedt, S. Richter, A. Weisheit, J.H. Schleifenbaum, and C. Haase, Mater. Des. (2018). https://doi.org/10.1016/j. matdes.2018.10.051.

7. F. Kies, M.B. Wilms, N. Pirch, K.G. Pradeep, J.H. Schleifenbaum, and C. Haase, Mater. Sci. Eng., A (2019). h ttps://doi.org/10.1016/j.msea.2019.138688.

8. T. Niendorf and F. Brenne, Mater. Charact. (2013). http s://doi.org/10.1016/j.matchar.2013.08.010.

9. T. Niendorf, S. Leuders, A. Riemer, H.A. Richard, T. Tröster, and D. Schwarze, Metall. Mater. Trans. B (2013). h ttps://doi.org/10.1007/s11663-013-9875-z. 
10. L.E. Murr, S.M. Gaytan, A. Ceylan, E. Martinez, J.L Martinez, D.H. Hernandez, B.I. Machado, D.A. Ramirez, F. Medina, and S. Collins, Acta Mater. (2010). https://doi.org/ 10.1016/j.actamat.2009.11.032.

11. A.A. Antonysamy, J. Meyer, and P.B. Prangnell, Mater. Charact. (2013). https://doi.org/10.1016/j.matchar.2013.07. 012 .

12. R.R. Dehoff, M.M. Kirka, F.A. List, K.A. Unocic, and W.J. Sames, Mater. Sci. Technol. (2014). https://doi.org/10.1179/ 1743284714Y.0000000697.

13. F. Geiger, K. Kunze, and T. Etter, Mater. Sci. Eng., A (2016). https://doi.org/10.1016/j.msea.2016.03.036.

14. H. Helmer, A. Bauereiß, R.F. Singer, and C. Körner, Mater. Sci. Eng., A (2016). https://doi.org/10.1016/j.msea.2016.05. 046.

15. F. Liu, X. Lin, C. Huang, M. Song, G. Yang, J. Chen, and W. Huang, J. Alloys Compd. (2011). https://doi.org/10.1016/ j.jallcom.2010.11.176

16. L.L. Parimi, G.A. Ravi, D. Clark, and M.M. Attallah, $M a-$ ter. Charact. (2014). https://doi.org/10.1016/j.matchar.201 3.12.012.

17. M. Simonelli, Y.Y. Tse, and C. Tuck, Metall. Mater. Trans. A (2014). https://doi.org/10.1007/s11661-014-2218-0.

18. L. Thijs, F. Verhaeghe, T. Craeghs, J. van Humbeeck, and J.-P. Kruth, Acta Mater. (2010). https://doi.org/10.1016/j.ac tamat.2010.02.004.

19. L. Thijs, K. Kempen, J.-P. Kruth, and J. van Humbeeck, Acta Mater. (2013). https://doi.org/10.1016/j.actamat.2012. 11.052 .

20. T. Wang, Y.Y. Zhu, S.Q. Zhang, H.B. Tang, and H.M. Wang, J. Alloys Compd. (2015). https://doi.org/10.1016/j.ja llcom.2015.01.256.

21. I. Yadroitsev, P. Krakhmalev, I. Yadroitsava, S. Johansson, and I. Smurov, J. Mater. Process. Technol. (2013). https://d oi.org/10.1016/j.jmatprotec.2012.11.014.

22. Q. Zhang, J. Chen, X. Lin, H. Tan, and W.D. Huang, J. Mater. Process. Technol. (2016). https://doi.org/10.1016/j.j matprotec.2016.07.011.

23. X. Zhou, K. Li, D. Zhang, X. Liu, J. Ma, W. Liu, and Z. Shen, J. Alloys Compd. (2015). https://doi.org/10.1016/j.ja llcom.2015.01.096.

24. P. Köhnen, C. Haase, J. Bültmann, S. Ziegler, J.H. Schleifenbaum, and W. Bleck, Mater. Des. (2018). https://doi. org/10.1016/j.matdes.2018.02.062.

25. M.F. Horstemeyer, Integrated Computational Materials Engineering (ICME) for Metals (Hoboken: Wiley, 2018).

26. G.B. Olson, Science (1997). https://doi.org/10.1126/science. 277.5330 .1237

27. M. Seifi, A. Salem, J. Beuth, O. Harrysson, and J.J. Lewandowski, JOM (2016). https://doi.org/10.1007/s11837-01 5-1810-0.

28. W. Yan, Y. Lian, C. Yu, O.L. Kafka, Z. Liu, W.K. Liu, and G.J. Wagner, Comput. Methods Appl. Mech. Eng. (2018). h ttps://doi.org/10.1016/j.cma.2018.05.004.

29. W. Yan, S. Lin, O.L. Kafka, Y. Lian, C. Yu, Z. Liu, J. Yan, S. Wolff, H. Wu, E. Ndip-Agbor, M. Mozaffar, K. Ehmann, J. Cao, G.J. Wagner, and W.K. Liu, Comput. Mech. (2018) https://doi.org/10.1007/s00466-018-1539-z.

30. W. Yan, S. Lin, O.L. Kafka, C. Yu, Z. Liu, Y. Lian, S. Wolff, J. Cao, G.J. Wagner, and W.K. Liu, Front. Mech. Eng. (2018). https://doi.org/10.1007/s11465-018-0505-y.

31. J. Smith, W. Xiong, W. Yan, S. Lin, P. Cheng, O.L. Kafka, G.J. Wagner, J. Cao, and W.K. Liu, Comput. Mech. (2016). https://doi.org/10.1007/s00466-015-1240-4.

32. D. Pal, N. Patil, K. Zeng, and B. Stucker, J. Manuf. Sci. Eng. (2014). https://doi.org/10.1115/1.4028580.

33. M.M. Francois, A. Sun, W.E. King, N.J. Henson, D. Tourret, C.A. Bronkhorst, N.N. Carlson, C.K. Newman, T. Haut, J. Bakosi, J.W. Gibbs, V. Livescu, S.A. Vander Wiel, A.J. Clarke, M.W. Schraad, T. Blacker, H. Lim, T. Rodgers, S. Owen, F. Abdeljawad, J. Madison, A.T. Anderson, J.-L. Fattebert, R.M. Ferencz, N.E. Hodge, S.A. Khairallah, and O. Walton, Curr. Opin. Solid State Mater. Sci. (2017). h ttps://doi.org/10.1016/j.cossms.2016.12.001.
34. L. Koschmieder, S. Hojda, M. Apel, R. Altenfeld, Y. Bami, C. Haase, M. Lin, A. Vuppala, G. Hirt, and G.J. Schmitz, Integr. Mater. Manuf. Innov. (2019). https://doi.org/10.100 7/s40192-019-00138-3.

35. S.A.H. Motaman, F. Roters, and C. Haase, Acta Mater. (2020). https://doi.org/10.1016/j.actamat.2019.12.003.

36. B.C. de Cooman, Y. Estrin, and S.K. Kim, Acta Mater. (2018). https://doi.org/10.1016/j.actamat.2017.06.046.

37. A. Saeed-Akbari, L. Mosecker, A. Schwedt, and W. Bleck, Metall. Mater. Trans. A (2012). https://doi.org/10.1007/s11 661-011-0993-4.

38. A. Saeed-Akbari, J. Imlau, U. Prahl, and W. Bleck, Metall. Mater. Trans. A (2009). https://doi.org/10.1007/s11661-0090050-8.

39. B. Hallstedt, A.V. Khvan, B.B. Lindahl, M. Selleby, and S. Liu, Calphad (2017). https://doi.org/10.1016/j.calphad.201 6.11.006.

40. A. Dumay, J.-P. Chateau, S. Allain, S. Migot, and O. Bouaziz, Mater. Sci. Eng., A (2008). https://doi.org/10.1016/ j.msea.2006.12.170.

41. S. Allain, J.-P. Chateau, O. Bouaziz, S. Migot, and N. Guelton, Mater. Sci. Eng., A (2004). https://doi.org/10.1016/ j.msea.2004.01.059.

42. A. Dick, T. Hickel, and J. Neugebauer, Steel Res. Int. (2009). https://doi.org/10.2374/SRI09SP015.

43. L. Vitos, J.-O. Nilsson, and B. Johansson, Acta Mater. (2006). https://doi.org/10.1016/j.actamat.2006.04.013.

44. C. Brandl, P.M. Derlet, and H. van Swygenhoven, Phys. Rev. B (2007). https://doi.org/10.1103/PhysRevB.76.054124.

45. A. Reyes-Huamantinco, P. Puschnig, C. Ambrosch-Draxl, O.E. Peil, and A.V. Ruban, Phys. Rev. B (2012). https://doi. org/10.1103/PhysRevB.86.060201.

46. A. Abbasi, A. Dick, T. Hickel, and J. Neugebauer, Acta Mater. (2011). https://doi.org/10.1016/j.actamat.2011.01.04 4.

47. X. Zhang, B. Grabowski, F. Körmann, A.V. Ruban, Y. Gong, R.C. Reed, T. Hickel, and J. Neugebauer, Phys. Rev. $B$ (2018). https://doi.org/10.1103/PhysRevB.98.224106.

48. O. Güvenc, F. Roters, T. Hickel, and M. Bambach, JOM (2015). https://doi.org/10.1007/s11837-014-1192-8.

49. D. Music, T. Takahashi, L. Vitos, C. Asker, I.A. Abrikosov, and J.M. Schneider, Appl. Phys. Lett. (2007). https://doi. org $/ 10.1063 / 1.2807677$.

50. S. Reeh, D. Music, T. Gebhardt, M. Kasprzak, T. Jäpel, S. Zaefferer, D. Raabe, S. Richter, A. Schwedt, J. Mayer, B. Wietbrock, G. Hirt, and J.M. Schneider, Acta Mater. (2012). https://doi.org/10.1016/j.actamat.2012.07.038.

51. D. Ma, M. Friák, J. von Pezold, J. Neugebauer, and D. Raabe, Acta Mater. (2015). https://doi.org/10.1016/j.actama t.2015.07.054

52. D. Ma, M. Friák, J. von Pezold, D. Raabe, and J. Neugebauer, Acta Mater. (2015). https://doi.org/10.1016/j.actama t.2014.10.044.

53. G.P.M. Leyson, L.G. Hector, and W.A. Curtin, Acta Mater. (2012). https://doi.org/10.1016/j.actamat.2012.06.020.

54. G.P.M. Leyson, L.G. Hector, and W.A. Curtin, Acta Mater. (2012). https://doi.org/10.1016/j.actamat.2012.03.037.

55. G.P.M. Leyson, W.A. Curtin, L.G. Hector, and C.F. Woodward, Nat. Mater. (2010). https://doi.org/10.1038/nmat281

56. H. Zhang, B. Johansson, R. Ahuja, and L. Vitos, Comput. Mater. Sci. (2012). https://doi.org/10.1016/j.commatsci.201 1.12.020.

57. S. Vannarat, M.H.F. Sluiter, and Y. Kawazoe, Phys. Rev. B (2001). https://doi.org/10.1103/PhysRevB.64.224203.

58. C. Haase, F. Tang, M.B. Wilms, A. Weisheit, and B. Hallstedt, Mater. Sci. Eng., A (2017). https://doi.org/10.1016/j. msea.2017.01.099.

59. S. Ewald, F. Kies, S. Hermsen, M. Voshage, C. Haase, and J.H. Schleifenbaum, Materials (Basel, Switzerland) (2019). https://doi.org/10.3390/ma12101706.

60. F. Kies, Y. Ikeda, S. Ewald, J.H. Schleifenbaum, B. Hallstedt, F. Körmann, and C. Haase, Scr. Mater. (2019). h ttps://doi.org/10.1016/j.scriptamat.2019.12.004. 
61. Y. Ikeda, I. Tanaka, J. Neugebauer, and F. Körmann, Phys. Rev. Mater. (2019). https://doi.org/10.1103/PhysRevMateri als.3.113603.

62. Y. Ikeda, B. Grabowski, and F. Körmann, Mater. Charact. (2019). https://doi.org/10.1016/j.matchar.2018.06.019.

63. O.N. Senkov, J.D. Miller, D.B. Miracle, and C. Woodward, Calphad (2015). https://doi.org/10.1016/j.calphad.2015.04. 009.

64. D. Miracle, J. Miller, O. Senkov, C. Woodward, M. Uchic, and J. Tiley, Entropy (2014). https://doi.org/10.3390/e1601 0494 .

65. K.G. Pradeep, C.C. Tasan, M.J. Yao, Y. Deng, H. Springer, and D. Raabe, Mater. Sci. Eng., A (2015). https://doi.org/10. 1016/j.msea.2015.09.010.

66. G. Vastola, G. Zhang, Q.X. Pei, and Y.-W. Zhang, JOM (2016). https://doi.org/10.1007/s11837-016-1890-5.

67. J. Yang and F. Wang, Int. J. Adv. Manuf. Technol. (2009). https://doi.org/10.1007/s00170-008-1785-x.

68. S.A. Khairallah and A. Anderson, J. Mater. Process. Technol. (2014). https://doi.org/10.1016/j.jmatprotec.2014.0 6.001 .

69. T.T. Roehling, S.S.Q. Wu, S.A. Khairallah, J.D. Roehling, S.S. Soezeri, M.F. Crumb, and M.J. Matthews, Acta Mater. (2017). https://doi.org/10.1016/j.actamat.2017.02.025.

70. C. Panwisawas, C.L. Qiu, Y. Sovani, J.W. Brooks, M.M. Attallah, and H.C. Basoalto, Scr. Mater. (2015). https://doi. org/10.1016/j.scriptamat.2015.04.016.

71. C. Panwisawas, C. Qiu, M.J. Anderson, Y. Sovani, R.P. Turner, M.M. Attallah, J.W. Brooks, and H.C. Basoalto, Comput. Mater. Sci. (2017). https://doi.org/10.1016/j.comm atsci.2016.10.011.

72. P. Köhnen, M. Létang, M. Voshage, J. Henrich Schleifenbaum, and C. Haase, Addit. Manuf. (2019). https://doi.org/ 10.1016/j.addma.2019.100914.

73. P. Lan and J. Zhang, Steel Res. Int. (2016). https://doi.org/ 10.1002/srin.201500022.

74. S.A. Khairallah, A.T. Anderson, A. Rubenchik, and W.E. King, Acta Mater. (2016). https://doi.org/10.1016/j.actamat. 2016.02.014.

75. C. Suryanarayana, Non-equilibrium Processing of Materials (Oxford: Pergamon, 1999).

76. A.B. Spierings, N. Herres, and G. Levy, Rapid Prototyp. J. (2011). https://doi.org/10.1108/13552541111124770.

77. J. Eiken, B. Böttger, and I. Steinbach, Phys. Rev. E (2006). https://doi.org/10.1103/PhysRevE.73.066122.

78. B. Böttger, J. Eiken, and M. Apel, Comput. Mater. Sci. (2015). https://doi.org/10.1016/j.commatsci.2015.03.003.

79. T.M. Rodgers, J.D. Madison, and V. Tikare, Comput. Mater. Sci. (2017). https://doi.org/10.1016/j.commatsci.2017.0 3.053 .

80. M.A. Groeber and M.A. Jackson, Integr. Mater. (2014). h ttps://doi.org/10.1186/2193-9772-3-5.

81. F. Roters, M. Diehl, P. Shanthraj, P. Eisenlohr, C. Reuber, S.L. Wong, T. Maiti, A. Ebrahimi, T. Hochrainer, H.-O. Fabritius, S. Nikolov, M. Friák, N. Fujita, N. Grilli, K.G.F. Janssens, N. Jia, P.J.J. Kok, D. Ma, F. Meier, E. Werner, M. Stricker, D. Weygand, and D. Raabe, Comput. Mater. Sci. (2019). https://doi.org/10.1016/j.commatsci.2018.04.03 0 .

82. O.C. Zienkiewicz, The Finite Element Method for Solid and Structural Mechanics, 6th ed. (Amsterdam: Elsevier, 2005).

83. M. Smith, Z. Guan, and W.J. Cantwell, Int. J. Mech. Sci. (2013). https://doi.org/10.1016/j.ijmecsci.2012.12.004.

84. B. Lozanovski, M. Leary, P. Tran, D. Shidid, M. Qian, P. Choong, and M. Brandt, Mater. Des. (2019). https://doi.org/ 10.1016/j.matdes.2019.107671.
85. C. de Formanoir, M. Suard, R. Dendievel, G. Martin, and S. Godet, Addit. Manuf. (2016). https://doi.org/10.1016/j.add ma.2016.05.001.

86. J.A. Koepf, D. Soldner, M. Ramsperger, J. Mergheim, M. Markl, and C. Körner, Comput. Mater. Sci. (2019). https://d oi.org/10.1016/j.commatsci.2019.03.004.

87. J.A. Koepf, M.R. Gotterbarm, M. Markl, and C. Körner, Acta Mater. (2018). https://doi.org/10.1016/j.actamat.2018. 04.030.

88. O. Zinovieva, A. Zinoviev, and V. Ploshikhin, Comput. Mater. Sci. (2018). https://doi.org/10.1016/j.commatsci.201 7.09.018.

89. Y. Lian, Z. Gan, C. Yu, D. Kats, W.K. Liu, and G.J. Wagner, Mater. Des. (2019). https://doi.org/10.1016/j.matdes.2 019.107672

90. Y. Lian, S. Lin, W. Yan, W.K. Liu, and G.J. Wagner, Comput. Mech. (2018). https://doi.org/10.1007/s00466-0171535-8.

91. X. Li and W. Tan, Comput. Mater. Sci. (2018). https://doi. org/10.1016/j.commatsci.2018.06.019.

92. S. Chen, G. Guillemot, and C.-A. Gandin, Acta Mater. (2016). https://doi.org/10.1016/j.actamat.2016.05.011.

93. S. Chen, G. Guillemot, and C.-A. Gandin, ISIJ Int. (2014) https://doi.org/10.2355/isijinternational.54.401.

94. C. Reuber, P. Eisenlohr, F. Roters, and D. Raabe, Acta Mater. (2014). https://doi.org/10.1016/j.actamat.2014.03.01 2.

95. N. Grilli, K.G.F. Janssens, J. Nellessen, S. Sandlöbes, and D. Raabe, Int. J. Plast. (2018). https://doi.org/10.1016/j.ijpla s.2017.09.015.

96. P. Shanthraj, L. Sharma, B. Svendsen, F. Roters, and D. Raabe, Comput. Methods Appl. Mech. Eng. (2016). https://d oi.org/10.1016/j.cma.2016.05.006.

97. C. Liu, P. Shanthraj, M. Diehl, F. Roters, S. Dong, J. Dong, W. Ding, and D. Raabe, Int. J. Plast. (2018). https://doi.org/ 10.1016/j.ijplas.2018.03.009.

98. A. Molinari, G.R. Canova, and S. Ahzi, Acta Metall. (1987). https://doi.org/10.1016/0001-6160(87)90297-5.

99. R.A. Lebensohn and C.N. Tomé, Acta Metall. Mater. (1993). https://doi.org/10.1016/0956-7151(93)90130-K.

100. R.A. Lebensohn, C.N. Tomé, and P.P. CastaÑeda, Philos. Mag. (2007). https://doi.org/10.1080/14786430701432619.

101. S.A.H. Motaman and U. Prahl, J. Mech. Phys. Solids (2019). https://doi.org/10.1016/j.jmps.2018.09.002.

102. S.A.H. Motaman, K. Schacht, C. Haase, and U. Prahl, Int J. Solids Struct. (2019). https://doi.org/10.1016/j.ijsolstr.2 019.05.028

103. A.L. Gurson, J. Eng. Mater. Technol. (1977). https://doi. org/10.1115/1.3443401.

104. V. Tvergaard, Advances in Applied Mechanics, Vol. 27 (Amsterdam: Elsevier, 1989), p. 83.

105. A. Needleman and V. Tvergaard, J. Mech. Phys. Solids (1987). https://doi.org/10.1016/0022-5096(87)90034-2.

106. Y. Hammi and M.F. Horstemeyer, Int. J. Plast. (2007). h ttps://doi.org/10.1016/j.ijplas.2007.03.010.

107. C.F. Niordson, Eur. J. Mech. A (2008). https://doi.org/10. 1016/j.euromechsol.2007.07.001.

108. N. Aravas and P. Ponte Castañeda, Comput Methods Appl. Mech. Eng. (2004). https://doi.org/10.1016/j.cma.2004.02.0 09

Publisher's Note Springer Nature remains neutral with regard to jurisdictional claims in published maps and institutional affiliations. 